\title{
Spinal cord compression in pseudohypoparathyroidism
}

\author{
DEREK R. CULLEN AND JOHN M. S. PEARCE
}

\begin{abstract}
From the Department of Neurology, the Regional Neurological Centre, Newcastle General Hospital, Newcastle upon Tyne 4
\end{abstract}

The syndrome of pseudohypoparathyroidism described by Albright, Burnett, Smith, and Parson (1942) has been well reviewed by MacGregor and Whitehead (1954) and by Mann, Alterman, and Gorman Hills (1962). The clinical features consist of mental retardation, epilepsy and attacks of tetany, as well as ectodermal defects such as alopecia, defective dentition, brittle nails, and cataracts. There are also certain characteristic somatic abnormalities. The patient has a moon face, a short stocky stature, and shortening of some of the metacarpals and metatarsals due to premature epiphyseal closure. The bone structure is normal but ectopic calcification can usually be seen in the basal ganglia and in the subcutaneous tissues. The diagnosis is confirmed by finding low serum calcium and high serum phosphorus levels. Dickson, Morita, Cowsert, Graves, and Meyer (1960) have recorded the occurrence of E.E.G. abnormalities in pseudohypoparathyroidism. The syndrome has also been associated with diabetes mellitus, diabetes insipidus, and hypothyroidism (Mann et al., 1962).

There has recently been controversy regarding the nosological status of the two conditions, which have been called pseudohypoparathyroidism and pseudopseudohypoparathyroidism. In the latter condition (Albright, Forbes, and Henneman, 1952) similar clinical and radiological abnormalities are found but the values of serum calcium and phosphorus are normal. Most workers now regard the latter condition as being an incompletely expressed form of the syndrome of pseudohypoparathyroidism (Dickson et al., 1960; Mann et al., 1962) and there seems to be little point in attempting to identify the two disorders as distinctive clinical entities.

The following case report concerns a young woman with pseudohypoparathyroidism who developed a progressive spastic paraplegia due to spinal cord compression caused by abnormal bone formation.

\section{CASE REPORT}

The patient, aged 31 , had been mentally retarded since childhood and had suffered from major epilepsy since the age of 7 years. There was no history suggestive of tetany. She presented with difficulty in walking and stiffness of both legs of gradual onset and slow progression over the course of one year. There had been no disturbance of sensation or of the sphincters; there was no history of injury.

On examination she had a large round face and slight alopecia (Fig. 1). The skin showed a mild degree of ichthyosis. Bilateral cataracts were visible and slit lamp examination showed these to be anterior and posterior subcapsular in position. The breasts were underdeveloped but there was a normal female distribution of hair. Her height was $4 \mathrm{ft} .7$ in. and she had a short neck. When asked to make a fist (Fig. 2), a dimple could be seen in the knuckle-line of each hand due to the presence of a shortened fourth metacarpal. There was also a bony contracture of each little finger. Chvostek's and Trousseau's signs were negative. There was no abnormality of the cranial nerves or in the upper limbs. She had a spastic paraplegia in flexion, with increased reflexes, clonus, and bilateral extensor plantar responses. There was a band of impaired pin-prick and touch sensation extending around the trunk at the level of the D10-11 sensory dermatomes. There was no obvious abnormality in the chest, cardiovascular system, or abdomen.

INVESTigations Haemoglobin was $14 \cdot 1 \mathrm{~g}$. \%, W.B.C. $5,600 /$ per c.mm., E.S.R. $7 \mathrm{~mm}$. in one hour. The blood urea level was $28 \mathrm{mg}$. \%, serum cholesterol $145 \mathrm{mg}$. \%, serum albumin $5 \cdot 4 \mathrm{~g}$. per $100 \mathrm{ml}$. and serum globulin $1.2 \mathrm{~g}$. per $100 \mathrm{ml}$. The Wassermann reaction was negative. A chest radiograph was normal. An E.C.G. was normal. Serum protein-bound iodine level was $5 \cdot 7 \mu \mathrm{g} . / 100 \mathrm{ml}$.

A radioactive tri-iodothyronine/resin uptake ratio to a control was 0.98 (normal range 0.82 to 1.28 ) (Clark, 1963). An E.E.G. showed changes which were largely non-specific. Chromosome studies performed on this patient (Dr. J. Gray) showed that she was a normal chromatin-positive female with 46 chromosomes.

Tests specifically related to parathyroid dysfunction Basal serum calcium was $8 \cdot 5,8 \cdot 6,8 \cdot 8 \mathrm{mg}$. per $100 \mathrm{ml}$. serum; basal serum inorganic phosphate $3.4,3.3,3.9 \mathrm{mg}$. per $100 \mathrm{ml}$. plasma; and serum alkaline phosphatase 5.5 K.A. units.

An Ellsworth-Howard test (1934) was performed and the results are seen in Fig. 3, which shows that there was no response to an intravenous injection of 200 U.S.P. units of parathormone, in contrast to the findings in normal subjects and in cases of idiopathic hypoparathyroidism in which there is a significant increase in urinary phosphate excretion. 


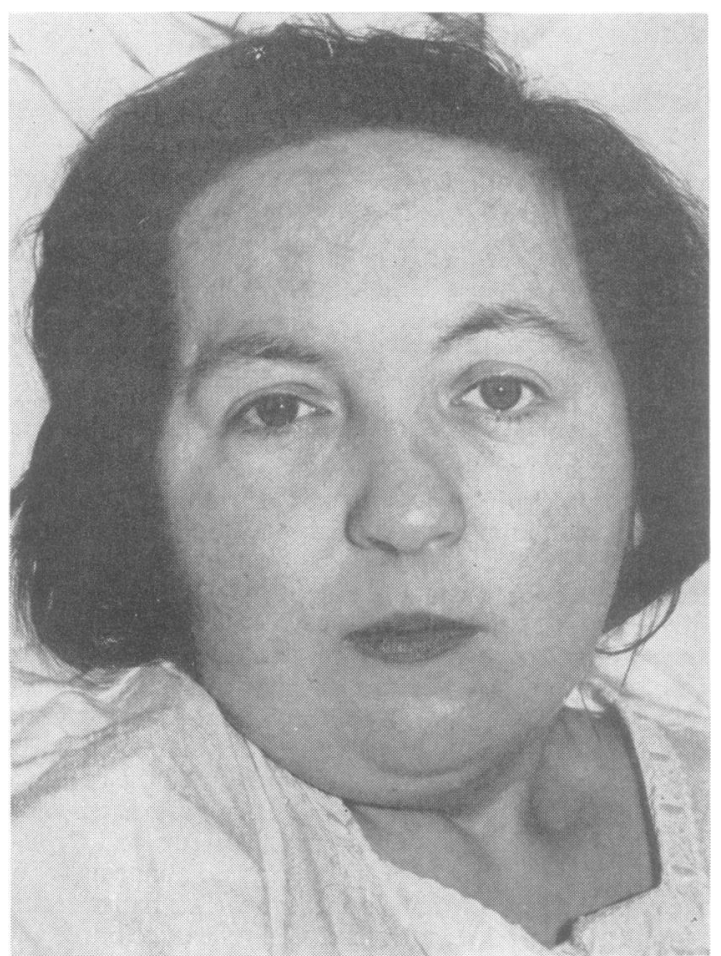

FIG. 1. Characteristic facies.

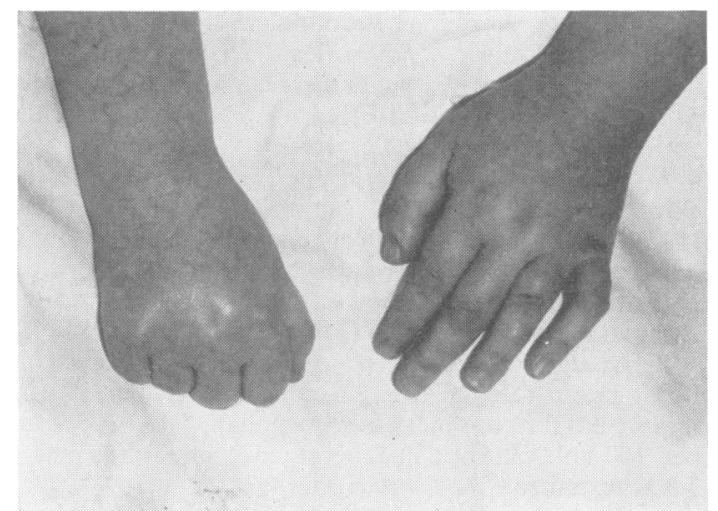

FIG. 2. Hands showing the dimple due to the shortened fourth metacarpal.

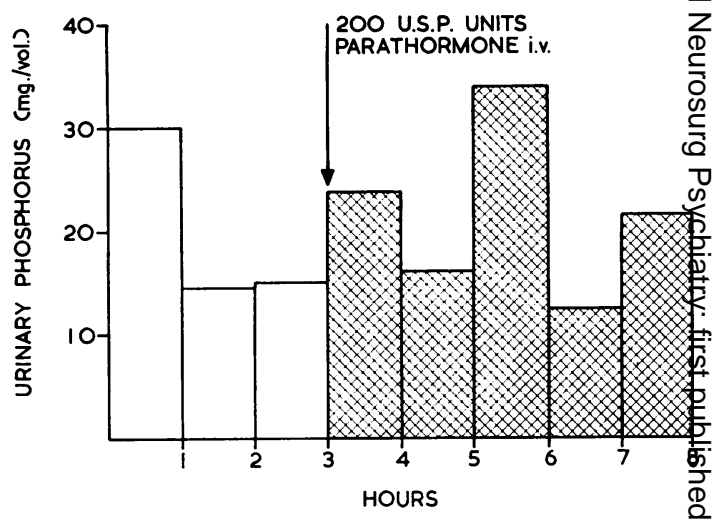

FIG. 3. The Ellsworth-Howard test.

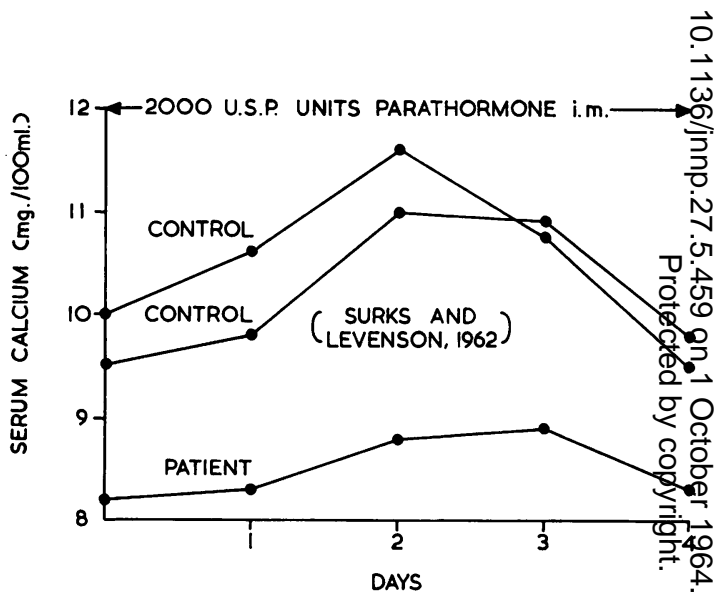

FIG. 4. The response of the serum calcium to injections parathormone.

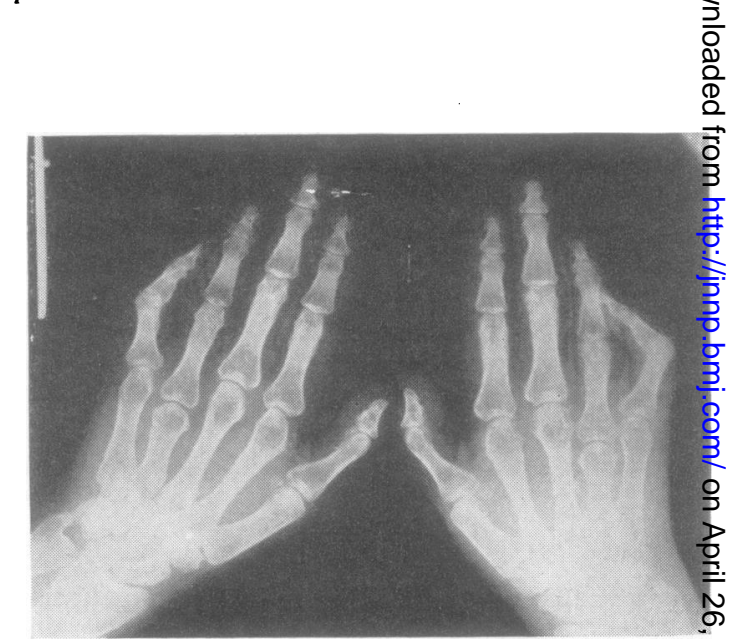

FIG. 5. Radiograph of hands. Note the shortened four metacarpal and soft tissue calcification. 


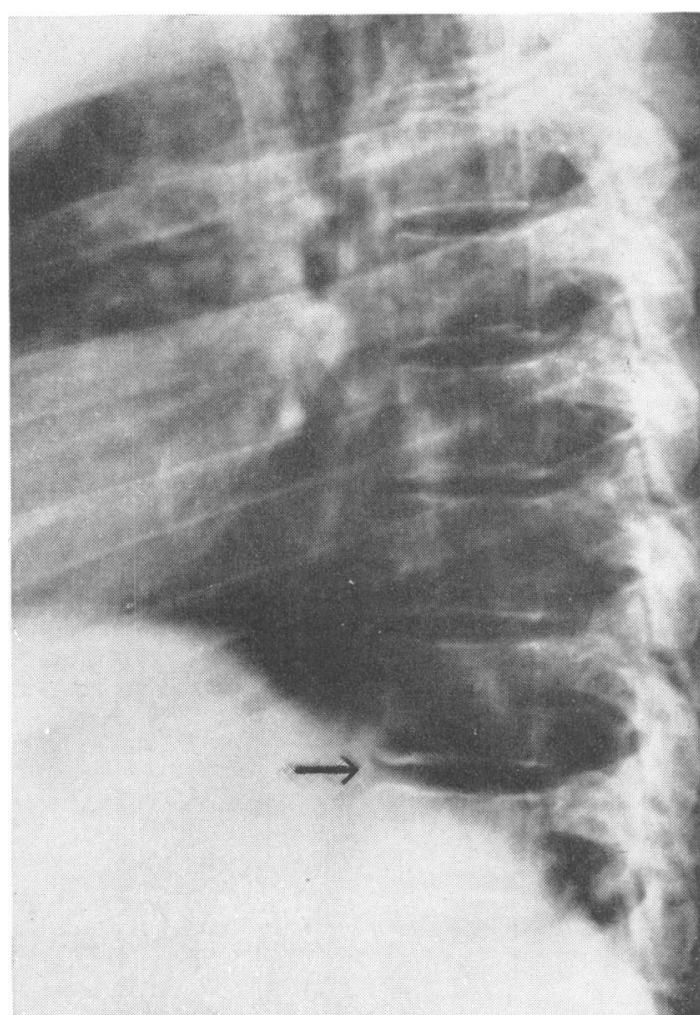

FIG. 6

FIG. 6. A lateral chest radiograph showing the calcification of the anterior longitudinal ligament of the D9-10 vertebrae.

FIG. 7. Myelogram showing the presence of a complete extradural block at the level of D10.

A three-day study of the serum calcium during and after daily intramuscular injections of 2,000 U.S.P. units of parathormone in divided dosage was performed (Surks and Levenson, 1962). This showed that the patient was refractory to the hormone as the serum calcium levels did not rise. The results are shown in Fig. 4, where results in normal controls are given for comparison.

The diagnosis of pseudohypoparathyroidism was confirmed by the failure of parathormone to produce an increase in the serum calcium or urinary phosphorus.

The striking radiological features in this case were the shortened fourth metacarpals and metatarsals and contracture of the fifth proximal interphalangeal joint of both hands, and the diffuse peppered soft tissue calcification (Fig. 5); bilateral calcification in the basal ganglia; the calcification seen in the anterior longitudinal ligament of the D9-10 vertebrae and the otherwise normal radiological appearance of the vertebral bodies and in particular of the pedicles (Fig. 6); the presence of a complete block at the level of D10 on myelography, using $6 \mathrm{ml}$.

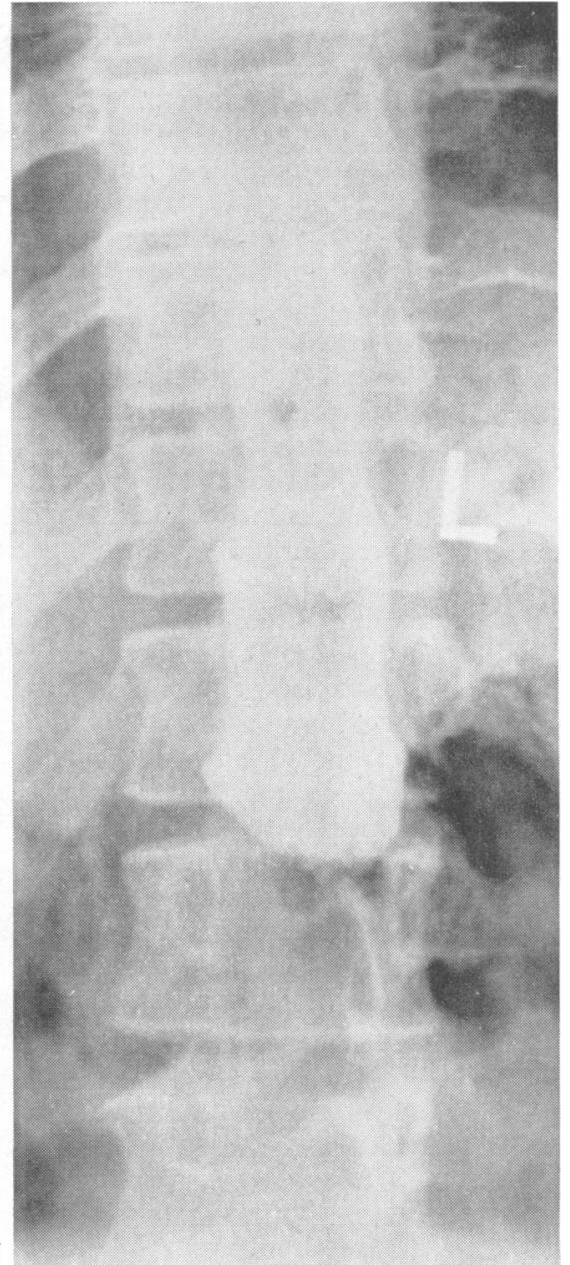

of Myodil injected by the lumbar route (Fig. 7). This appeared to be due to an extradural compression.

At operation a lower dorsal laminectomy was performed by Mr. J. Hankinson. The lamina of D10 was abnormally thick and hard, and by removing the bone above and below, a bony constriction of the theca was demonstrated. There was a marked pulsation of the theca above and no pulsation below. The bony constriction was removed and the dura mater at this point had to be incised to free the cord which then appeared normal. The bony swelling compressing the cord appeared simply to be an abnormally thickened lamina.

Following operation the patient improved steadily and is now walking unaided.

\section{DISCUSSION}

The mental retardation, epilepsy, and the characteristic body habitus, facies and hands, together with the presence of lens opacities, are strongly suggestive 
of pseudohypoparathyroidism, and the associated radiological changes undeniably confirm this diagnosis. We are of the opinion that pseudohypoparathyroidism and pseudo-pseudohypoparathyroidism are one entity, the presence of normal values for serum calcium and serum phosphorus in the latter condition being due to the absence of the stresses of skeletal growth on the metabolism (Mann et al., 1962) after the phase of adolescence.

The biochemical investigation of this condition is difficult. The Ellsworth-Howard test is unreliable as is shown by the inconsistency of the results obtained by different investigators (Dent, 1953; MacGregor and Whitehead, 1954; Surks and Levenson, 1962). The response of the serum calcium to large doses of parathormone is an improvement on this test, particularly if there is truth in the suggestion (MacGregor and Whitehead, 1954) that the parathyroid extract used in Britain has been affected by manufacturing processes, and while retaining its hypercalcaemic power, has lost its ability to increase urinary excretion of phosphorus. In this patient the presence of resistance to parathyroid hormone has been adequately demonstrated by both tests.

The main interest of this case lies in the association of a spastic paraplegia with pseudohypoparathyroidism. Although ectopic bone formation is characteristic of this condition, it usually occurs in the subcutaneous tissues or in the basal ganglia. To the best of our knowledge this is the first report of excessive bone formation inside the vertebral canal in pseudohypoparathyroidism. In this particular case it seems highly probable that the paraplegia was associated with the metabolic disorder, but we wou角 stress that in other similar cases the paraplegia cou be caused by an unrelated intrinsic or extrinse lesion of the spinal cord and such cases will always demand myelographic investigation.

\section{SUMMARY}

A case of pseudohypoparathyroidism presentin with a spastic paraplegia is described. The investiga tions and the operative findings of an overgrowth of: bone from a vertebral lamina which produce compression of the spinal cord are discussed.

We are indebted to Dr. J. N. Walton for permission te

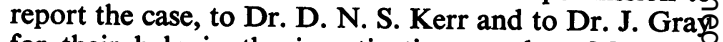
for their help in the investigations, and to Mr. John Hankinson who was responsible for the surgical manage? ment. We also wish to thank the Department of Photo $\overrightarrow{0}$ graphy at the University of Newcastle for the illustrations;and Miss Riches and Miss Allan for secretarial assistance

\section{REFERENCES}

Endocrinology, 30, 922.
, Forbes, A. P., and Henneman, P. H. (1952). Trans. Ass. Am Phycns, 65, 337.

Clark, F. (1963). Lancet, 2, 167.

Dent, C. E. (1953). Proc. roy. Soc. Med., 46, 291.

Dickson, L. G., Morita, Y., Cowsert, E. J., Graves, J., and Meser? J. S. (1960). J. Neurol. Neurosurg. Psychiat., 23, 33.

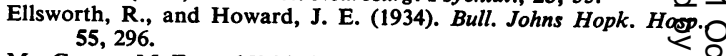
398.

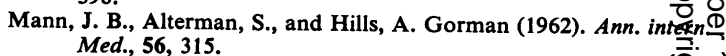

Surks, M. I., and Levenson, D. (1962). Ibid., 56, 282. 